\title{
FLT3-ITD Mutation and FLT3 Ligand Plasma Level Were Not Associated with One-Year Survival of Indonesian Acute Myeloid Leukemia Patients
}

This article was published in the following Dove Press journal: OncoTargets and Therapy

\author{
Ikhwan Rinaldi' \\ Melva Louisa ${ }^{2}{ }^{2}$ \\ Resti Mulya Sari ${ }^{3}$ \\ Elly Arwanih'
}

'Division of Hematology and Medical Oncology, Department of Internal Medicine, Cipto Mangunkusumo National General Hospital, Faculty of Medicine, Universitas Indonesia, Jakarta, Indonesia; ${ }^{2}$ Department of Pharmacology and Therapeutics, Faculty of Medicine, Universitas Indonesia, Jakarta, Indonesia; ${ }^{3}$ Division of Hematology and Medical Oncology, Department of Internal Medicine, Dharmais Cancer Hospital, Faculty of Medicine, Universitas Indonesia, Jakarta, Indonesia
Correspondence: Ikhwan Rinaldi Cipto Mangunkusumo National General Hospital, Jakarta, Indonesia

Email ikhwanrinaldi@gmail.com
Objective: To analyze the association of FLT3-ITD mutation and FLT3 ligand plasma level with one-year survival of Indonesian acute myeloid leukemia (AML) patients.

Methods: A prospective cohort study was conducted to determine the association between FLT-3-ITD mutation and FLT3 ligand plasma level with one-year survival of Indonesian AML patients. In the study, a total of 51 AML patients were obtained from two tertiary hospitals in Indonesia from year 2018 to 2020. Inclusion criteria were de novo AML male and female patients aged $\geq 18$ years old. Exclusion criteria were prior myelodysplastic syndrome and patients that refused to participate in the study. FLT3-ITD genotype of patients was then analyzed using PCR method while FLT3 ligand plasma level was measured using ELISA method. Patients were then followed-up for 1 year or until death occurred with survival as the measured outcome. Association between independent and dependent variable were analyzed by cox regression proportional hazard.

Results: Eleven patients $(21.5 \%)$ in this study had FLT3-ITD mutation. The median age of AML patients was 45 (18-71) years, and the median blast percentage was 50\% (5-87\%). After one-year follow-up, 33 (64.7\%) patients had died. The median survival of AML patients was 6 months. Univariate analysis showed no association between FLT3-ITD mutation status (HR: 1.051 ; 95\% CI: 0.483-2.286; P: 0.901) and FLT3 ligand plasma level (HR: 0.798; 95\% CI: $0.347-1.837 ; \mathrm{p}=0.596$ ), and age (HR: $1.283 ; 95 \% \mathrm{CI}: 0.575-2.862 ; \mathrm{p}=0.542$ ) with one-year survival of AML patients, but multivariate analysis showed association between GFR with oneyear survival of AML patients in this cohort (HR: 4.053; 95\% CI: 1.469-11.183; $\mathrm{p}=0.007$ ).

Conclusion: One-year survival of AML patients in Indonesia is not affected by FLT3-ITD mutation and FLT3 ligand plasma level. However, GFR showed association with one-year survival of AML patient in this cohort study.

Keywords: acute myeloid leukemia, one-year survival, FLT3-ITD, FLT3 Ligand Plasma

\section{Introduction}

Acute Myeloid Leukemia (AML) is the most common form of acute leukemia in adults. The incidence of AML worldwide according to Global Burden of Cancer Study (GLOBOCAN) reached 4.7/100.000 with 5-year prevalence about $1.5 \%$ in 2012. ${ }^{1}$ Most cases of AML occur in age above 60 years old which makes AML a disease of older adults. ${ }^{2}$ The mortality of AML, according to GLOBOCAN in 2018 reached 3.5/100.000 a year which increased from the previous study in 2014 . $^{1}$

The prognosis of AML patient is influenced by several factors such as age, clinical parameters, cytogenetic abnormality, and somatic mutation. ${ }^{3}$ Based on several studies 
on AML, Fms-like tyrosine kinase 3 internal tandem duplication (FLT3-ITD) mutation is observed as one of the most common mutations in AML. ${ }^{4-8}$ This mutation causes activation of anti-apoptotic and proliferation in leukemia cells, which is generally associated with poor prognostic outcome in patients and higher relapse rate in AML. The one-year survival rate of AML patients with FLT3-ITD mutation is lower than patients without the mutation. ${ }^{9-12}$

Another factor that affects prognosis of AML patients is plasma FLT3 plasma ligand level. FLT3 mutant receptor which activates proliferation in leukemic cells is shown to be hyperresponsive towards FLT3 ligand. ${ }^{12}$ Therefore, FLT3 ligand can maximize the activation of mutant FLT3 receptor and theoretically enhances proliferation of leukemic cells. ${ }^{10,13}$ Additionally, FLT3 ligand interferes with tyrosine kinase inhibitors' effects such as sorafenib and imatinib which may reduce treatment responsiveness. ${ }^{12}$ Interestingly, the use of chemotherapy actually increases the level of FLT3 ligand which might promote relapse. ${ }^{14}$

Research on survival based on both FLT3-ITD mutation status and plasma FLT3 ligand level has never been conducted in Indonesia. Hence, this is the first cohort FLT3 research conducted in Indonesia and is aimed as a preliminary study to analyze association between FLT3-ITD mutation and FLT3 ligand plasma level with one-year survival of AML patients.

\section{Methods}

\section{Patients}

This is a prospective cohort study from July 2018 to July 2020 on Cipto Mangunkusumo National General Hospital and Dharmais Cancer Hospital in Jakarta. The inclusion criteria used for the study was male and female patients aged above 18 years old and diagnosed with de novo AML. AML was diagnosed based on WHO criteria. Patients that received intensive chemotherapy or hydroxyurea therapy were included in the study. Exclusion criteria were AML patients that transformed from myelodysplastic syndrome and patients that were prepared for bone marrow transplantation. Additionally, patients with incomplete medical records and patients that refused to provide informed consent in the study were not included.

\section{Ethics}

This study was ethically approved by the Institutional Review Committee of Cipto Mangunkusumo National General Hospital and Dharmais Cancer Hospital (No. 536/UN2.F1/ ETIK/PPM.00.02/2019). The written informed consent was obtained from all patients in accordance with the Declaration of Helsinki. All patients were treated according to the hospital's clinical pathway and were observed for one year.

\section{Detection of FLT3-ITD and FLT3 Ligand Plasma Concentration}

Both FLT3-ITD mutation and FLT3 ligand plasma level analysis were conducted in Pharmacology Laboratory of Faculty of Medicine, Universitas Indonesia using peripheral blood sample. The location of mutation FLT3-ITD was restricted to exons 11 and 12 from FMS Related Receptor Tyrosine Kinase 3 (FLT3) gene as previously reported. ${ }^{4-8,15}$ Genomic DNA amplification was performed by PCR method using primer 11F: 5'- GCAATTTAGGTATGAAAGC CAGC -3', and primer 12R: 5'- CTTTCAGCATTT TGACGGCAACC -3'. Primers was designed using GeneBank data NM_004119. DNA extraction was performed with DNA extraction kit (ZYMO RESEARCH) with peripheral blood sample given EDTA.

\section{Polymerase Chain Reaction}

Polymerase chain reaction (PCR) was performed to determine FLT3-ITD genotype of the patient. A master mix to amplify the DNA was made up from: Genomic DNA, 12.5 $\mu \mathrm{L}$ MYTAQ buffer, $10 \mu$ molar primer, and $\mathrm{dH}_{2} \mathrm{O}$ with final volume of $25 \mu \mathrm{L}$.

To carry out the PCR reaction, A Veriti Thermal Cycler (Applied Biosystems 9700) was used. All reactions were performed in 35 cycles, 15 seconds denaturation step at $95{ }^{\circ} \mathrm{C}, 15$ seconds annealing step at $56^{\circ} \mathrm{C}, 15$ seconds extension step at $72^{\circ} \mathrm{C}$, and a final extension for 10 minutes at $72{ }^{\circ} \mathrm{C}$. The PCR products were run on $2 \%$ agarose gel. The gels were made from $2 \%$ agarose dissolved in tris-acetic acidethylenediaminetetraacetic acid (EDTA) buffer (TAE) $(40 \mathrm{mM}$ tris, $20 \mathrm{mM}$ acetic acid, $1 \mathrm{mM}$ EDTA) with $0.5 \mu \mathrm{g} / \mathrm{mL}$ ethidium bromide. Once made, the solution was poured into a cast and allowed to set. Gels were run for 35 minutes at 100 volts. After that, the gel was visualized through a UV light transilluminator.

The product of PCR amplification of genomic DNA for the FLT3-ITD gene was a band with $329 \mathrm{bp}$, if a mutation exists, it has more than one band in which the other band has product more than $329 \mathrm{bp}$. The PCR amplification result of genomic DNA for the mutation of FLT3-ITD gene result was cut out from an agarose gel and then were sequenced using the sanger sequencing method. Measurement of FLT3 ligand plasma level was performed with FLT3 Ligand ELISA kit (Thermo Scientific) according to manufacturer instructions. 


\section{Statistical Analyses}

Statistical analyses were carried out in SPSS version 20.0 (IBM Corp., Armonk, NY, USA). For proportional hazard assumption test consisting of Kaplan-Meier method, Ln Ln survival test, and global test, STATA version 15 was used. For Schoenfeld's global test, variables were considered to fulfill proportional hazard assumption test if $\mathrm{p}$ value $>0.05$. Meanwhile, for both Kaplan-Meier and ln ln survival method, variables fulfill proportional hazard assumption test if no curves intersect.

Descriptive statistics were used to calculate baseline characteristics among FLT3-ITD mutant group and FLT3ITD wildtype group. Categorical data is presented with frequency and percentages. Continuous data is presented with either mean or median.

Time of diagnosis to the time of death was used to calculate one-year survival . Primary survival analysis was performed using Kaplan-Meier method and cox proportional hazards regression models to calculate hazard ratios and $95 \%$ confidence intervals. $\mathrm{P}$ value of $<0.05$ was considered to be statistically significant.

\section{Result}

\section{Patient Characteristics and FLT3 Prevalence}

Baseline characteristics of demographic, clinical, and molecular data of 51 de novo AML patients are presented in Table 1. Eleven patients out of 51 patients $(21.5 \%)$ had FLT3-ITD mutation. All subjects were followed up for one year or until death occurred. The median age at the time of diagnosis of the entire cohort was 45 years old (age range, 18-71). Nine patients $(17.6 \%)$ were aged $\geq 60$ years. Male gender accounted for $39.2 \%$ of the study cohort. The mean hemoglobin level of the patients was $8.13 \pm 1.961$ with median total leukocyte level of 15,560 (1640-282,090). In addition, the blast percentage median was $50 \%$ (range, 5-87\%). A total of 9 patients received " $3+7$ " intensive chemotherapy regimen. The rest of the cohort either receive hydroxyurea or best supportive care.

Table 2 showed that 8 FLT3-ITD mutation patients were aged $\leq 60$ and 3 patients aged $>60$.

\section{Total Overall Survival}

Median overall survival of 51 patients was 6 months $(95 \%$ CI; 3.473-8.527) (Figure 1).

\section{Median Survival Outcome Based on FLT3-ITD Genotype}

Median survival was 6 months for FLT3-ITD mutant group and 5 months for FLT3-ITD wildtype group (Figure 2).

\section{Median Survival of FLT3 Ligand Plasma Level}

In group with FLT3 ligand $\geq 4.1 \mathrm{pg} / \mathrm{mL}$, the median survival was 6 months, Meanwhile, in group with $<4.1 \mathrm{pg} / \mathrm{mL}$, the median survival was 5 months (Figure 3).

Table I Demographic and Baseline Characteristics of Patients from 2018 to 2019

\begin{tabular}{|c|c|c|c|}
\hline Characteristics & FLT3-ITD Mutant $(n=I I)$ & FLT3-ITD Wild-Type $(n=40)$ & Total $(n=5 I)$ \\
\hline Male (n) (\%) & $5(10 \%)$ & $15(30 \%)$ & $20(39.2 \%)$ \\
\hline Age (Year) (Median) & $47(30-71)$ & $43.5(18-68)$ & $45(|8-7|)$ \\
\hline BMI (SD) & $21.252 \pm 2.645$ & $21.089 \pm 3.616$ & $21.12 \pm(3.406)$ \\
\hline Hemoglobin (Median) & $8.4(3.1-12.7)$ & $8.2 \pm 4.2-11.8$ & $8.2(3.1-12.7)$ \\
\hline Leukocyte (\%) (Median) & $14,590(1860-109,120)$ & $15,860(1640-282,090)$ & $15,560(1640-282,090)$ \\
\hline Blast (\%) (Median) & $50.5(5-83)$ & $47.5(9-87)$ & $50(5-87)$ \\
\hline Basophil (\%) (Median) & $0(0-0)$ & $0(0-2)$ & $0(0-2)$ \\
\hline Eosinophil (\%) (Median) & $0(0-2)$ & $0(0-35.5)$ & $0(0-35)$ \\
\hline Segmented Neutrophil (\%) (Median) & $18(I-30.67)$ & $7.25(0-53)$ & $8(0-53)$ \\
\hline Band Neutrophil (\%) (Median) & $5(0-52.7)$ & $\mid(0-3 \mid)$ & I $(0-52.7)$ \\
\hline Lymphocyte (\%) (Median) & $15(4-84.6)$ & I2.5 (0-74.5) & $13(0-84.6)$ \\
\hline Monocyte (\%) (Median) & $5(0-17.4)$ & $4(0-93)$ & $4.5(0-93)$ \\
\hline Platelet (Median) & $56,400(19,000-95,000)$ & $38,500(7000-221,820)$ & $40,000(7000-22 I, 820)$ \\
\hline SGOT (median) & $25(1 \mathrm{I}-32)$ & $24(9-103)$ & $24(9-103)$ \\
\hline SGPT (median) & $19.81(1-95)$ & $26.5(4-107)$ & $26(1-107)$ \\
\hline GFR (median) & $94.9(33-118.1)$ & $88.87(3|.85-2| 5.22)$ & $90.41(31.85-215.22)$ \\
\hline FLT-3 Ligand Concentration ( $\mathrm{pg} / \mathrm{mL}$ ) (Median) & $0(0-11.86)$ & $0(0-32.04)$ & $0(0-32.04)$ \\
\hline Intensive Chemotherapy (n) (\%) & I (9.1\%) & $8(20 \%)$ & $9(17.6 \%)$ \\
\hline Non-intensive Chemotherapy (n) (\%) & $10(90.9 \%)$ & $32(80 \%)$ & $42(82.3 \%)$ \\
\hline
\end{tabular}


Table 2 The Proportion of Age and FLT3 Ligand Concentration Based on FLT3-ITD Status

\begin{tabular}{|c|l|l|l|}
\hline Variables & $\begin{array}{l}\text { FLT3-ITD } \\
\text { Mutant (n= I I) }\end{array}$ & $\begin{array}{l}\text { FLT3-ITD Wild- } \\
\text { Type (n= 40) }\end{array}$ & $\begin{array}{l}\text { Total } \\
(\mathbf{n}=5 \text { I) }\end{array}$ \\
\hline $\begin{array}{l}\text { Age } \\
>60 \\
\leq 60\end{array}$ & 3 & 6 & \\
\hline $\begin{array}{l}\text { FLT3 Ligand } \\
\text { Concentration } \\
\geq 4.1 \mathrm{pg} / \mathrm{mL} \\
<4.1 \mathrm{pg} / \mathrm{mL}\end{array}$ & 3 & 34 & 92 \\
\hline
\end{tabular}

\section{Proportional Hazard Assumption Test}

Proportional hazard assumption test consisting of KaplanMeier method, In ln survival method test and Schoenfeld's global test was performed on each variable. However, only Schoenfeld's global test was chosen as the requirement for proportional hazard assumption due to higher objectivity than other methods. ${ }^{16}$ Based on Schoenfeld's global test, all variables fulfill proportional hazard assumption test. Hence all variables were then selected forunivariate analysis.

\section{Univariate and Multivariate Analysis}

Univariate analysis was performed on 13 variables (Table 4). FLT3-ITD and FLT3 ligand as primary variables in this study were not associated with one-year survival. Univariate cox regression result with $\mathrm{P}$ value of $\leq 0.25$ were selected for multivariate analysis. Those variables beside intensive

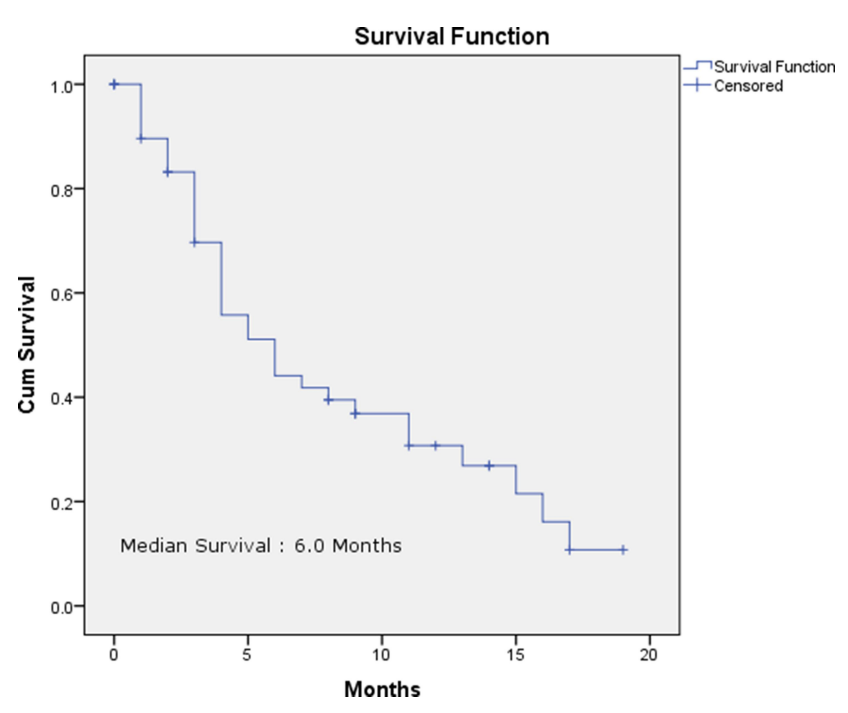

Figure I Cumulative Survival of All Patients.

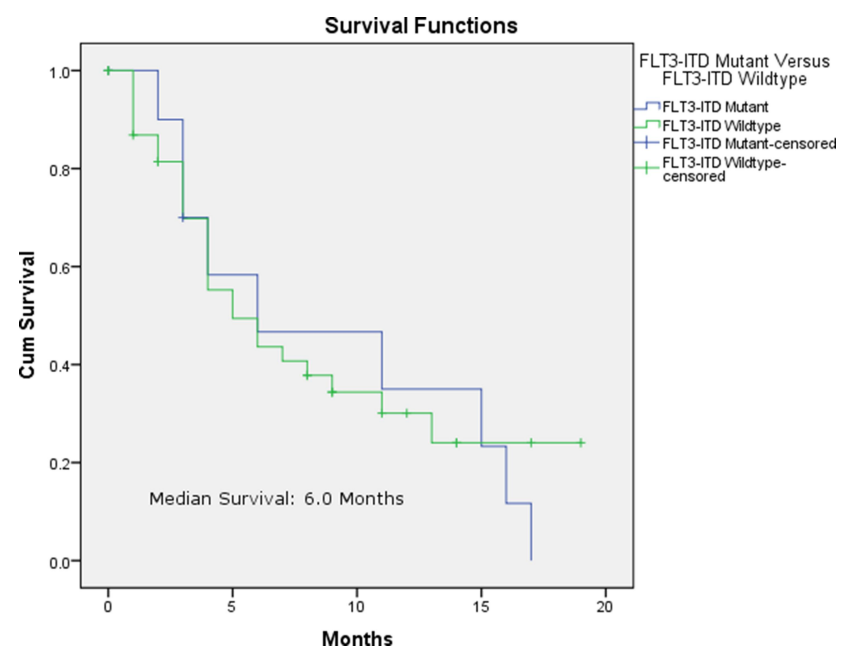

Figure 2 Kaplan-Meier Survival Curve of Patients Based on FLT3-ITD Mutation Status.

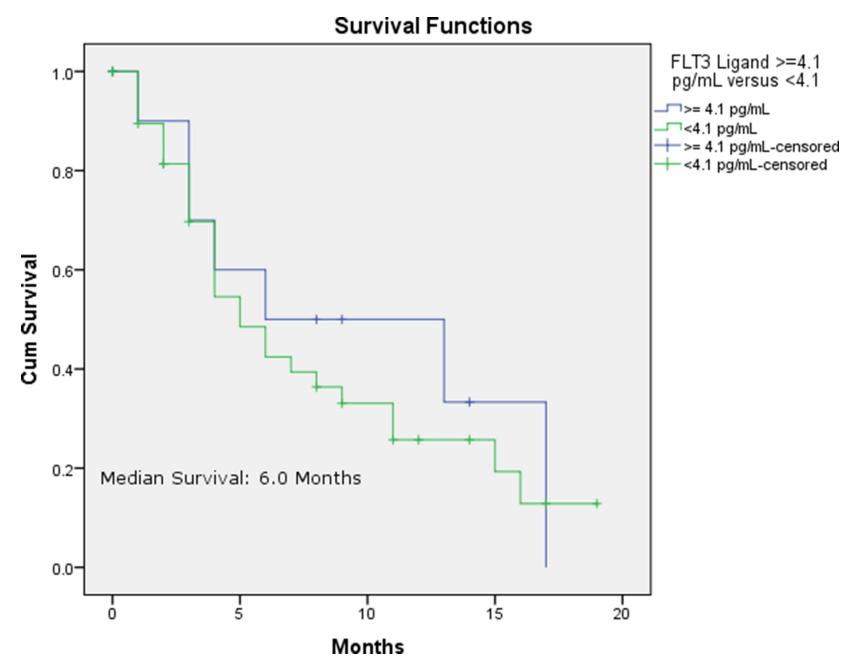

Figure 3 Kaplan-Meier Survival Curve of Patients Based on FLT3 Ligand Plasma Level.

chemotherapy were BMI (HR: 0.582; 95\% CI: 0.575-2.862; P: 0.240), Platelet (HR: 0.615; 95\% CI: $0.307-1.233$; P: 0.170), SGPT (HR: 0.479; 95\% CI: 0.183-1.251; P: 0.133), and GFR (HR: 3.062; 95\% CI: 1.174-7.987; P: 0.022) (Table 4). Multivariate Cox Regression analysis was performed, showing only GFR (HR: 4.053; 95\% CI: 1.469-11.183; P: 0.007 ) remained as significant variable.

\section{Discussion}

FLT3-ITD mutation is one of the most commonly identified gene mutations in AML while being an infrequent mutation in MDS and acute lymphocytic leukemia. ${ }^{15,17}$ In our cohort, the prevalence of FLT3-ITD mutation of 
Table 3 Proportional Hazard Assumption Test of Variables Based on Ln Ln Probability and Global Test

\begin{tabular}{|l|l|l|l|l|l|}
\hline No. & Variables & $\begin{array}{l}\text { Kaplan-Meier } \\
\text { Method }\end{array}$ & $\begin{array}{l}\text { Ln Ln Survival } \\
\text { Method }\end{array}$ & $\begin{array}{l}\text { Schoenfeld's Global } \\
\text { Test }\end{array}$ & $\begin{array}{l}\text { Proportional Hazard } \\
\text { Assumption }\end{array}$ \\
\hline I & FLT3-ITD Status & Intersect & Intersect & 0.1312 & Fulfilled \\
2 & FLT3 Ligand Concentration & Intersect & Intersect & 0.5986 & Fulfilled \\
3 & Intensive Chemotherapy & Intersect & No Intersect & 0.5909 & Fulfilled \\
4 & Age & Intersect & No intersect & 0.3385 & Fulfilled \\
5 & Gender & Intersect & Intersect & 0.2385 & Fulfilled \\
6 & BMI & Intersect & Intersect & 0.5596 & Fulfilled \\
7 & Hemoglobin & Intersect & Intersect & 0.4032 & Fulfilled \\
8 & Leukocyte & Intersect & Intersect & 0.7912 & Fulfilled \\
9 & Blast & Intersect & Intersect & 0.8003 & Fulfilled \\
10 & Platelet & No Intersect & No Intersect & 0.8248 & Fulfilled \\
II & SGOT & No Intersect & No intersect & 0.9362 & Fulfilled \\
I2 & SGPT & Intersect & Intersect & 0.8501 & Fulfilled \\
13 & GFR & Intersect & Intersect & 0.6149 & Fulfilled \\
\hline
\end{tabular}

Table 4 Univariate and Multivariate Analysis

\begin{tabular}{|c|c|c|c|c|c|}
\hline \multirow[t]{2}{*}{ No. } & \multicolumn{3}{|c|}{ Univariate Analysis } & \multicolumn{2}{|c|}{ Multivariate Analysis } \\
\hline & Variables & Hazard Ratio (95\% Cl) & P Value & Hazard Ratio $(95 \% \mathrm{Cl})$ & $P$ value \\
\hline 1 & Intensive Chemotherapy & $0.477(0.167-1.358)$ & 0.165 & & \\
\hline 2 & FLT3-ITD mutation & 1.051 (0.483-2.286) & 0.901 & & \\
\hline 3 & FLT3 Ligand & $0.798(0.347-1.837)$ & 0.596 & & \\
\hline 4 & Age & $1.283(0.575-2.862)$ & 0.542 & & \\
\hline 5 & Gender & $1.635(0.82 I-3.258)$ & 0.162 & $2.054(0.987-4.240)$ & 0.054 \\
\hline 6 & BMI & $0.582(0.236-1.435)$ & 0.240 & & \\
\hline 7 & Hemoglobin & $1.028(0.505-2.092)$ & 0.939 & & \\
\hline 8 & Leukocyte & $1.436(0.722-2.856)$ & 0.303 & & \\
\hline 9 & Blast & $0.944(0.285-3.129)$ & 0.925 & & \\
\hline 10 & Platelet & $0.615(0.307-1.233)$ & 0.170 & & \\
\hline II & SGOT & $0.532(0.16 \mathrm{I}-\mathrm{I} .753)$ & 0.300 & & \\
\hline 12 & SGPT & $0.479(0.183-|.25|)$ & 0.133 & & \\
\hline 13 & GFR & 3.062 (1.174-7.987) & 0.022 & $4.053(1.469-11.183)$ & 0.007 \\
\hline
\end{tabular}

de novo AML patients was $21.5 \%$. This is similar with the prevalence of other studies in Latin America, Japan, and Germany with FLT3-ITD mutation prevalence of $20.28 \%$, $22.8 \%$, and $20.4 \%$, respectively. ${ }^{10,18,19}$ A study by Notopuro et al in Indonesia with 20 samples also showed a similar prevalence of $20 \%{ }^{20}$ Therefore, our study shows that FLT3-ITD mutation occurs with similar prevalence in Indonesian AML patients.

The median age of FLT3-ITD mutant group in our study was 47 years which is similar to a study done in China with median age of 50 years old. ${ }^{21}$ Females account for 31 patients $(60.78 \%)$ in this study. In contrast, other recent studies involving FLT3 recruited more male patients. ${ }^{22,23}$ The mean BMI of our cohort is within normal range (18.5-22.9) based on
Asia-Pacific guidelines. ${ }^{24}$ In contrast to another study which has 121 patients with BMI above $30 \mathrm{~kg} / \mathrm{m}^{2}$, our cohort has less patients with obesity. ${ }^{25}$

Our study population had anemia with a median hemoglobin of 8.2 (3.1-12.7). In a study by Scholl et al, the median hemoglobin was $5.4(3.2-8.5){ }^{26}$ Meanwhile, another study by $\mathrm{Ni}$ et al had median of $6.9(2.6-14.3) .{ }^{23}$ Both of these studies had lower hemoglobin than our cohort. Nevertheless, the hemoglobin level is still low as there is reduced erythropoiesis caused by blast proliferation in the bone marrow due to AML. ${ }^{3}$

The median leukocyte in this study was 15,560 (1640$282,090)$. Compared to other studies, the median leukocyte in our cohort is much lower. ${ }^{22,23,26}$ The median blast level of this 
study is similar to a study by $\mathrm{Ni}$ et al. ${ }^{23}$ Additionally, we did not detect any difference in leukocyte level and blast percentage between mutant and wildtype group. These findings are in concordance with two studies in Iran and Middle East but different from other studies from other countries including Japan, China, and Europe. ${ }^{21,27-31}$ For platelet level, the cohort in this study had higher median level than the study by Ni et al but similar with the study by Scholl et al. ${ }^{23,26}$ Based on higher hemoglobin level and lower leukocyte level, the cohort in his study may have better prognosis when compared with other AML studies.

Level of FLT3 ligand plasma below $4.1 \mathrm{pg} / \mathrm{mL}$ were more common in FLT3-ITD mutant group in our study. However, the median level of FLT3 ligand plasma in this study is much lower than other studies. ${ }^{14,32}$

No difference was detected in survival based on factors of FLT3-ITD mutation status, FLT3-ITD ligand level, and age in our study. The median survival of our cohort was 6 months which is lower than median survival of studies by Ni et al and Niparuck et al with median of 9.7 months and 9 months respectively. ${ }^{23,33}$ It is possible that better treatment in their studies caused longer median survival.

This study did not observe any significance of FLT3ITD mutation on one-year survival outcome (HR 1.051 (0.483-2286); p: 0 0.91). ${ }^{34,35}$ This result is similar to two other studies by Ma et al and Miglino et al with higher sample size than this study of 320 patients in China (HR: 1.33; 95\% CI: $0.88-2.01$; P: 0.174$\}$ and 100 patients in Italy \{HR: 1.35 (95\% CI: 0.71-2.59) P: 0.35$\}$, respectively. Our group previously conducted a systematic review and meta-analysis of several studies with the conclusion of FLT3-ITD mutation being detrimental for AML survival. ${ }^{36}$ It is possible that racial differences may impact the prognosis despite the same gene mutations, hence highlighting that race may be an important factor on the prognosis of mutations in leukemia. An example is shown in a study with cytogenetically homogenous cohort by Abraham et al where Caucasians had better survival than Africans and Hispanics. ${ }^{37}$

Our analysis of FLT3 ligand plasma level showed that there was no effect of FLT3 ligand level in AML survival (HR: 0.798 ; 95\% CI: $0.347-1.837 ; p=0.596$ ). Again, this is contradictory with the results of other studies despite both studies also including patients receiving intensive chemotherapy. ${ }^{14,32}$ FLT-3 ligand plasma level is prognostically good when the level rises during treatment. Furthermore, FLT3 ligand plasma level is present in AML patients irrespective of FLT3-ITD mutation. ${ }^{14}$
Finally, we also did not find any association of age with AML survival in our cohort (HR: 1.283; 95\% CI: 0.575-2.862; $\mathrm{p}=0.542$ ) despite studies by Mosse et al with 258 patients and Krauter et al with 98 patients showing that age is an important prognostic factor in FLT3-ITD. ${ }^{38,39}$ However, the study by Krauter et al only included patients up to 60 years old with median age of 47 years, contrary with our study which involved 9 patients $>60$ years old in statistical analysis. ${ }^{39}$

All 13 variables were subjected to univariate analysis. In our study, we did not find any association of BMI with survival. According to an AML study with 314 patients, obesity causes worse prognosis in AML patients. ${ }^{25}$ However, this study was conducted in United States using BMI cutoff from WHO guidelines, whereas cutoffs from Asia-Pacific guideline are more suitable for Asian cohort. ${ }^{40}$ Nevertheless, a meta-analysis conducted by $\mathrm{Li}$ et al involving 26 studies showed that higher BMI is associated with worse overall survival in acute promyelocytic leukemia (APL).$^{41}$ Interestingly, no correlation between BMI and survival was observed in non-APL AML by the meta-analysis.

Univariate analysis found no association of age with survival (HR 1.283; 95\% CI: 0.575-2.862) p: 0.542). This is similar to a study by Padilha et al that also found there is no difference of survival in patients with age less or more than 60 years old (median survival of 12.4 months for the group aged less than or equal to 60 years versus 8.2 months for the group older than 60 years $(p$ value $=$ $0.2227 ;$ OR $=0.6676 ; 95 \% \mathrm{CI}=0.3488-1.278) .{ }^{42}$ Related to FLT3-ITD mutation, another study found that FLT3-ITD mutation was a strong marker for poor survival in young patients (60 years), but not in older patients $(60-74$ years $) .{ }^{43}$

Both leukocyte and blast were not associated with survival in our study. Possible explanation includes lower leukocyte and blast level in this study. As explained above, it is possible that lower leukocyte and blast level when compared to other studies confer a better prognosis in this study. ${ }^{4,44}$

In multivariate analysis, only GFR (HR: 4.053; 95\% CI: $1.469-11.183$; P: 0.007) had significant association with survival. It is well established that impaired kidney function is a universally independent prognostic factor of survival, including for leukemia. For gender variable, it did not achieve statistical significance (HR: 2.054; $95 \%$ CI: 0.987-4.240; P: 0.054). However, the confidence interval for gender is more precise than the confidence interval of GFR.

The limitation of our study is the lack of cytogenetic and immunophenotyping data. It is noted that cytogenetic 
and immunophenotyping abnormalities may also affect hemopoietic cell survival and proliferation. ${ }^{45,46}$ An additional limitation of this study is the relatively small number of the sample size when compared with other studies but still narrow of CI.

\section{Conclusion}

Our study observed the same prevalence of FLT3-ITD mutation in AML when compared with other studies. The analysis in our cohort showed no association between the FLT3-ITD mutation and FLT3 ligand concentration with one-year survival. Lower kidney function was associated with poor AML patient's one-year survival. Further study with higher number of patients is probably needed to confirm the findings in this study.

\section{Acknowledgment}

The authors are grateful to Eka Widya Khoirinal, Sri Widyasari, Lintang, Kevin Winston, and Doddy for their tremendous help in gathering data to be used for this study and writing the manuscript.

\section{Disclosure}

This study was funded by the Grant from Indonesian Ministry of Research, Technology and Higher Education (Ristekdikti), 2020. The authors report no other conflicts of interest in this work.

\section{References}

1. Bray F, Ferlay J, Soerjomataram I, Siegel RL, Torre LA, Jemal A. Global cancer statistics 2018: GLOBOCAN estimates of incidence and mortality worldwide for 36 cancers in 185 countries. CA Cancer J Clin. 2018;68(6):394-424. doi:10.3322/caac.21492

2. Shallis RM, Wang R, Davidoff A, Ma X, Zeidan AM. Epidemiology of acute myeloid leukemia: recent progress and enduring challenges. Blood Rev. 2019;36:70-87. doi:10.1016/j.blre.2019.04.005

3. Saultz JN, Garzon R. Acute myeloid leukemia: a concise review. J Clin Med. 2016;5(3):33. doi:10.3390/jcm5030033

4. de Jonge HJM, Valk PJM, de Bont ESJM, et al. Prognostic impact of white blood cell count in intermediate risk acute myeloid leukemia: relevance of mutated NPM1 and FLT3-ITD. Haematologica. 2011;96 (9):1310-1317. doi:10.3324/haematol.2011.040592

5. Kiyoi H, Naoe T, Yokota S, et al. Internal tandem duplication of FLT3 associated with leukocytosis in acute promyelocytic leukemia Leukemia Study Group of the Ministry of Health and Welfare (Kohseisho). Leukemia. 1997;11(9):1447-1452. doi:10.1038/sj. leu. 2400756

6. Kottaridis PD, Gale RE, Frew ME, et al. The presence of a FLT3 internal tandem duplication in patients with acute myeloid leukemia (AML) adds important prognostic information to cytogenetic risk group and response to the first cycle of chemotherapy: analysis of 854 patients from the United Kingdom Medical Research Council AML 10 and 12 trials. Blood. 2001;98(6):1752-1759. doi:10.1182/ blood.v98.6.1752
7. Yokota S, Kiyoi H, Nakao M, et al. Internal tandem duplication of the FLT3 gene is preferentially seen in acute myeloid leukemia and myelodysplastic syndrome among various hematological malignancies. A study on a large series of patients and cell lines. Leukemia. 1997;11(10):1605-1609. doi:10.1038/sj.leu.2400812

8. Nakao M, Yokota S, Iwai T, et al. Internal tandem duplication of the flt3 gene found in acute myeloid leukemia. Leukemia. 1996;10 (12):1911-1918.

9. Cuervo-Sierra J, Gómez-Almaguer D, Jaime-Pérez JC, et al. Prevalence of FLT3 mutations in acute myeloid leukemia: a multicenter Latin America Study. Blood. 2013;122(21):4979. doi:10.1182/blood.V122.21.4979.4979

10. Cuervo-Sierra J, Jaime-Pérez JC, Martínez-Hernández RA, et al. Prevalence and clinical significance of FLT3 mutation status in acute myeloid leukemia patients: a Multicenter Study. Arch Med Res. 2016;47(3):172-179. doi:10.1016/j.arcmed.2016.06.003

11. Krum EA, Yamamoto M, Chauffaille MDLLF. Prevalence of FMS-like tyrosine kinase 3/internal tandem duplication (FLT3/ITD + ) in de novo acute myeloid leukemia patients categorized according to cytogenetic risk. Sao Paulo Med J. 2009;127(1):23-27. doi:10.1590/S1516-31802009000100006

12. Levis M. FLT3/ITD AML and the law of unintended consequences. Blood. 2011;117(26):6987-6990. doi:10.1182/blood-2011-03340273

13. Burnatt G, Licínio MA, Gaspar PC, et al. Analysis of the presence of FLT3 gene mutation and association with prognostic factors in adult and pediatric acute leukemia patients. Braz J Pharm Sci. 2017;53(2). doi:10.1590/s2175-97902017000216105

14. Peterlin P, Gaschet J, Guillaume T, et al. FLT3 ligand plasma levels in acute myeloid leukemia. Haematologica. 2019;104(6):e240-e243. doi:10.3324/haematol.2018.209460

15. Nakao M, Janssen JW, Erz D, Seriu T, Bartram CR. Tandem duplication of the FLT3 gene in acute lymphoblastic leukemia: a marker for the monitoring of minimal residual disease. Leukemia. 2000;14 (3):522-524. doi:10.1038/sj.leu.2401695

16. Abeysekera WWM, Sooriyarachchi MR. Use of schoenfeld's global test to test the proportional hazards assumption in the cox proportional hazards model: an application to a clinical study. J Natl Sci Found Sri Lanka. 2009;37(1):41-51. doi:10.4038/ jnsfsr.v37i1.456

17. Xu F, Taki T, Yang HW, et al. Tandem duplication of the FLT3 gene is found in acute lymphoblastic leukaemia as well as acute myeloid leukaemia but not in myelodysplastic syndrome or juvenile chronic myelogenous leukaemia in children. Br J Haematol. 1999;105 (1):155-162. doi:10.1111/j.1365-2141.1999.01284.x

18. Thiede C, Steudel C, Mohr B, et al. Analysis of FLT3-activating mutations in 979 patients with acute myelogenous leukemia: association with FAB subtypes and identification of subgroups with poor prognosisPresented in part at the 42nd Annual Meeting of the American Society of Hematology, December 1-5,2000, San Francisco, CA (abstract 2334). Blood. 2002;99(12):4326-4335. doi:10.1182/blood.v99.12.4326

19. Kiyoi H, Naoe T, Nakano Y, et al. Prognostic implication of FLT3 and N-RAS gene mutations in acute myeloid leukemia. Blood. 1999;93(9):3074-3080.

20. Notopuro PB, Jusak N, Harianto N. Detection of FLT3 gene mutations in patients with acute myeloid leukemia in Surabaya, Indonesia: a Single-Center Study. Iran J Blood Cancer. 2020;12(2):54-57.

21. Wang L, Xu W, Meng H, et al. FLT3 and NPM1 mutations in Chinese patients with acute myeloid leukemia and normal cytogenetics. $J$ Zhejiang Univ Sci B. 2010;11(10):762-770. doi:10.1631/jzus.B1000052

22. Kurosawa S, Yamaguchi $\mathrm{H}$, Yamaguchi $\mathrm{T}$, et al. The prognostic impact of FLT3-ITD, NPM1 and CEBPa in cytogenetically intermediate-risk AML after first relapse. Int J Hematol. 2020;112 (2):200-209. doi:10.1007/s12185-020-02894-x 
23. Ni J, Hong J, Long Z, Li Q, Xia R, Zeng Q. Mutation profile and prognostic relevance in elderly patients with de novo acute myeloid leukemia treated with decitabine-based chemotherapy. Int $J$ Lab Hematol. 2020;42(6):849-857. doi:10.1111/ijlh.13299

24. Pan W-H, Yeh W-T. How to define obesity? Evidence-based multiple action points for public awareness, screening, and treatment: an extension of Asian-Pacific recommendations. Asia Pac J Clin Nutr. 2008;17(3):370-374.

25. Dhakal P, Lyden E, Lee A, et al. Effects of obesity on overall survival of adults with acute myeloid leukemia. Clin Lymphoma Myeloma Leuk. 2020;20(3):e131-e136. doi:10.1016/j.clml.2019.11.001

26. Scholl S, Theuer C, Scheble V, et al. Clinical impact of nucleophosmin mutations and Flt3 internal tandem duplications in patients older than $60 \mathrm{yr}$ with acute myeloid leukaemia. Eur J Haematol. 2008;80 (3):208-215. doi:10.1111/j.1600-0609.2007.01019.x

27. Rezaei N, Arandi N, Valibeigi B, Haghpanah S, Khansalar M, Ramzi M. FMS-Like Tyrosine Kinase 3 (FLT3) and nucleophosmin 1 (NPM1) in Iranian adult acute myeloid leukemia patients with normal karyotypes: mutation status and clinical and laboratory characteristics. Turk J Hematol. 2017;34(4):300-306.

28. Dehbi H, Kassogue Y, Nasserddine S, Quessar A, Nadifi S. FLT3ITD incidence and FLT-D835 mutations in acute myeloid leukemia patients with normal karyotype in morocco: a Preliminary Study. Middle East J Cancer. 2013;4(1):1-5.

29. Notopuro PB, Nugraha J, Utomo B, Notopuro H. The association of FLT3-ITD gene mutation with bone marrow blast cell count, CD34, cyclin D1, Bcl-xL and hENT1 expression in acute myeloid leukemia patients. Iran $J$ Pathol. 2020;15(4):306-312. doi:10.30699/ ijp.2020.122579.2328

30. Zhang Q, Wu X, Cao J, Gao F, Huang K. Association between increased mutation rates in DNMT3A and FLT3-ITD and poor prognosis of patients with acute myeloid leukemia. Exp Ther Med. 2019;18(4):3117-3124. doi:10.3892/etm.2019.7891

31. Fröhling S, Schlenk RF, Breitruck J, et al. Prognostic significance of activating FLT3 mutations in younger adults (16 to 60 years) with acute myeloid leukemia and normal cytogenetics: a study of the AML Study Group Ulm. Blood. 2002;100(13):4372-4380. doi:10.1182/ blood-2002-05-1440

32. Milne P, Wilhelm-Benartzi C, Grunwald MR, et al. Serum Flt3 ligand is a biomarker of progenitor cell mass and prognosis in acute myeloid leukemia. Blood Adv. 2019;3(20):3052-3061. doi:10.1182/ bloodadvances.2019000197

33. Niparuck P, Limsuwanachot N, Pukiat S, et al. Cytogenetics and FLT3-ITD mutation predict clinical outcomes in non transplant patients with acute myeloid leukemia. Exp Hematol Oncol. 2019;8 (1):1-4. doi:10.1186/s40164-019-0127-z

34. Ma Q-L, Wang J-H, Wang Y-G, et al. High IDH1 expression is associated with a poor prognosis in cytogenetically normal acute myeloid leukemia. Int $J$ Cancer. 2015;137(5):1058-1065. doi:10.1002/ijc. 29395
35. Miglino M, Colombo N, Pica G, et al. WT1 overexpression at diagnosis may predict favorable outcome in patients with de novo non-M3 acute myeloid leukemia. Leuk Lymphoma. 2011;52 (10):1961-1969. doi:10.3109/10428194.2011.585673

36. Rinaldi I, Louisa M, Wiguna FI, Budiani E, Mahardhika JC, Hukmi K. Prognostic significance of Fms-like tyrosine kinase 3 internal tandem duplication mutation in non-transplant adult patients with acute myeloblastic leukemia: a systematic review and meta-analysis. Asian Pac J Cancer Prev. 2020;21(10):2827-2836. doi:10.31557/APJCP.2020.21.10.2827

37. Abraham I, Patel AA, Zhang Y, Liu LC, Frankfurt O, Khan I. Impact of race on outcomes in intermediate risk acute myeloid leukemia. Blood. 2018;132(Supplement 1):3603. doi:10.1182/blood-2018-99115156

38. Mosse CA, Fitzhenry F, LeNoue-Newton M, et al. Impact of age on utilization and prognostic value of FLT3 and NPM1 testing in acute myeloid leukemia. J Clin Oncol. 2018;36(15_suppl):e19008. doi:10.1200/JCO.2018.36.15_suppl.e19008

39. Krauter J, Wagner K, Damm F, et al. FLT3-ITD and age are the major prognostic factors in relapsed AML with normal karyotype. Blood. 2010;116(21):1719. doi:10.1182/blood.V116.21.1719.1719

40. WHO Expert Consultation. Appropriate body-mass index for Asian populations and its implications for policy and intervention strategies. Lancet Lond Engl. 2004;363(9403):157-163. doi:10.1016/S01406736(03)15268-3

41. Li S, Chen L, Jin W, et al. Influence of body mass index on incidence and prognosis of acute myeloid leukemia and acute promyelocytic leukemia: a meta-analysis. Sci Rep. 2017;7(1):1-10. doi:10.1038/ s41598-017-18278-x

42. Padilha SL, Souza EJDS, Matos MCC, Domino NR. Acute myeloid leukemia: survival analysis of patients at a university hospital of Paraná. Rev Bras Hematol Hemoter. 2015;37(1):21-27. doi:10.1016/j.bjhh.2014.11.008

43. Juliusson G, Jädersten M, Deneberg S, et al. The prognostic impact of FLT3-ITD and NPM1 mutation in adult AML is age-dependent in the population-based setting. Blood Adv. 2020;4(6):1094-1101. doi:10.1182/bloodadvances.2019001335

44. Greenwood MJ, Seftel MD, Richardson C, et al. Leukocyte count as a predictor of death during remission induction in acute myeloid leukemia. Leuk Lymphoma. 2006;47(7):1245-1252. doi:10.1080/ 10428190600572673

45. Hong W-J, Medeiros BC. Unfavorable-risk cytogenetics in acute myeloid leukemia. Expert Rev Hematol. 2011;4(2):173-184. doi:10.1586/ehm.11.10

46. Costa AFO, Menezes DL, Pinheiro LHS, et al. Role of new immunophenotypic markers on prognostic and overall survival of acute myeloid leukemia: a systematic review and meta-analysis. Sci Rep. 2017;7(1):1-11. doi:10.1038/s41598-017-00816-2
OncoTargets and Therapy

\section{Publish your work in this journal}

OncoTargets and Therapy is an international, peer-reviewed, open access journal focusing on the pathological basis of all cancers, potential targets for therapy and treatment protocols employed to improve the management of cancer patients. The journal also focuses on the impact of management programs and new therapeutic agents and protocols on patient perspectives such as quality of life, adherence and satisfaction. The manuscript management system is completely online and includes a very quick and fair peer-review system, which is all easy to use. Visit http://www.dovepress.com/ testimonials.php to read real quotes from published authors. 